Available online at GSC Online Press Directory

GSC Biological and Pharmaceutical Sciences

e-ISSN: 2581-3250, CODEN (USA): GBPSC2

Journal homepage: https://www.gsconlinepress.com/journals/gscbps

(RESEARCH ARTICLE)

\title{
Efficient protocol for mass micropropagation of Artemisia annua L.
}

\author{
Zayova Ely Georgieva ${ }^{1,}{ }^{*}$, Nedev Trendafil Atanasov ${ }^{1}$, Petrova Detelina Hristova ${ }^{2}$, Zhiponova Miroslava \\ Konstantinova ${ }^{2}$ and Chaneva Ganka Todorova ${ }^{2}$ \\ ${ }^{1}$ Department of Applied Genetics and Plant Biotechnology, Institute of Plant Physiology and Genetics, Bulgarian Academy \\ of Sciences, Acad. G. Bonchev Street, Bldg. 21, 1113 Sofia, Bulgaria. \\ ${ }^{2}$ Department of Plant Physiology, Faculty of Biology of the Sofia University "St. Kliment Ohridski", Sofia, Bulgaria.
}

Publication history: Received on 16 October 2018; accepted on 28 October 2018

Article DOI: https://doi.org/10.30574/gscbps.2018.5.2.0119

\begin{abstract}
An efficient protocol for mass micropropagation of Artemisia annua L. was developed. The shoots were in vitro cultivated on a full and half strengths MS supplemented with BAP and IBA for shoot and root induction from stem tip explants. Maximum number of shoots (19.1) with an average shoot height of $3.6 \mathrm{~cm}$ was achieved at full MS medium + $1.0 \mathrm{mg} / \mathrm{L} \mathrm{BAP}$, after four weeks of cultivation. The best plant rooting (100\%), with 7.4 average roots' number per explant and average root length of $15.1 \mathrm{~cm}$, was obtained at $1 / 2 \mathrm{MS}$ medium $+0.1 \mathrm{mg} / \mathrm{L} \mathrm{IBA}+2.0 \%$ sucrose, after five weeks of cultivation. Under these growing conditions, an increase of total phenolic and flavonoid content of $A$. annua tissues was registered. The multiplied plants were successfully ex vitro adapted and 65\% survival was achieved on the mixture of soil, perlite and sand (2: 1: $1 \mathrm{v} / \mathrm{v} / \mathrm{v}$ ) used for acclimatization. The amounts of phenols and flavonoids, as well as total antioxidant activity of ex vitro plants, were significantly higher compared to those in the in vitro plants, but similar to the levels measured in vivo. The effective protocol for shoot micropropagation that was developed, could enable a large scale commercial production of $A$. annua.
\end{abstract}

Keywords: Artemisia annua L.; Micropropagation; Antioxidant activity

\section{Abbreviations \\ MS - Murashige and Skoog; GA3 - Gibberellic Acid; BAP - 6-Benzylaminopurine; IBA - 3-Indole Butyric Acid}

\section{Introduction}

Artemisia (Artemisia annua L., Asteraceae), a native of China, is a medicinally important plant, widely used for the production of the anti-malarial drug artemisinin [1, 2]. Artemisia has been applied in the traditional medicine, for the treatment of diabetes, depression, insomnia and stress, to clear the lymphatic system and in the oncotherapy. It is also used as an antiseptic, antispasmodic, digestive, expectorant, purgative and stimulating agent. The bioactive compounds isolated from A. annua, such as flavonoids, phenols, sesquiterpene lactones, have been reported to possess antibacterial, antioxidant, cytotoxic and antiinflammatory properties, and also a potent anticancer influence [3, 4]. The drug artemisinin has shown some anticancer effect in in vitro and animal cell experiments but there is still insufficient evidence for human cancer assays [5]. The production of artemisinin was reported by hairy root culture of $A$. annua in vitro, where the explants were infected with Agrobacterium rhizogenes to promote hairy root induction [6]. The conventional propagation of Artemisia by seeds is a constraint for its production due to its tiny seeds. The in vitro cultivation is a method for producing improved regenerants under controlled condition, especially under conditions where seeds are scarce and expensive to purchase. Micropropagation enables rapid rate of clonal multiplication of an

\footnotetext{
${ }^{*}$ Corresponding author

E-mail address: e_I_y@abv.bg
}

Copyright (C) 2018 Author(s) retain the copyright of this article. This article is published under the terms of the Creative Commons Attribution Liscense 4.0. 
elite plant species, allowing production of disease-free, genetically stable and uniform progenies. Most reports suggest a strong influence of genotype on the proliferation process [7].

An efficient method for in vitro micropropagation, shoot induction and regeneration of $A$. annua has been recently developed $[8,9]$. The average shoot and root length of plants regenerated from seeds, was optimal for elongation after cultivation on medium contained $0.1 \mathrm{mg} / \mathrm{L}$ kinetin combined with $0.01 \mathrm{mg} / \mathrm{L}$ naphthaleneacetic acid (NAA). Single shoots formed on auxin free MS medium [10] fortified with $0.025 \mathrm{mg} / \mathrm{L} \mathrm{BA}$, gave the highest number of nodes. Callus formation was evident at concentrations above $0.05 \mathrm{mg} / \mathrm{L} \mathrm{BA}$ in combination with $0.01 \mathrm{mg} / \mathrm{L}$ NAA [11]. Similarly, the stimulating effect of plant growth regulators on shoot formation was reported for other species from the genus Artemisia such as A. judicia [12]; A. scorpia [13]; A. vulgaris [14]; A. absinthium [15]; A. sieberi [16] and A. nilagirica var. nilagirica [17]. Shoot buds developed precociously from tip explants cultured on MS medium supplemented with different cytokinins. Among the different types of cytokinins that were tested, the maximum shoot induction was obtained on MS medium supplemented with BAP $(0.5-1.0 \mathrm{mg} / \mathrm{L})$. The superiority of BAP over other cytokinins in a tissue culture system has been well demonstrated in our studies on Stevia rebaudiana Bertoni $[18,19]$.

A. annua is a widely studied species due to the biological effects of its extracts [20]. Phenolic compounds are among the most important bioactive molecules found in higher amounts in A. annua tissues and flavones, flavone glycosides, coumarins and phenolic acids are the most representative phenolic compounds [21,22]. Further, as it is well known, the radical scavenging capacities of medicinal plants correlates with their phenolic content [23, 24]. The phenolic extracts of $A$. annua have shown significant antioxidant and antitumor activity [25] and their antioxidant properties have been were reported in several in vitro tests and in vivo model systems [26].

Taking into account the role of phenols in plants, it has been emphasized their importance in plant stress responses and further adaptation to the environmental changes [27]. Flavonoids, in particular, are involved in plants interactions and response to the environmental stress factors, due to their prominent antioxidant properties [28]. Thus, the synthesis and accumulation of secondary metabolites could be strongly influenced by varying environmental conditiond, specific to the different habitats. In this regard, we have suggested that in vitro procedures could change the amounts of natural antioxidants such as phenols and flavonoids and it is worth them to be analyzed. The aim of the present study was focused on the development of efficient protocol for mass micropropagation of $A$. annua plants combined with the investigation of its antioxidant properties.

\section{Material and methods}

\subsection{Plant material and sterilization of the explants}

The experiments were carried out at the Department of Applied Genetics and Plant Biotechnology, Institute of Plant Physiology and Genetics (IPPG), Bulgarian Academy of Sciences and Department of Plant Physiology, Faculty of Biology, Sofia University "St. Kliment Ohridski. The healthy mother plants of A. annua were maintained in the greenhouse of IPPG (Figure 1). One-year-old plants were used as a source of explants. Stem tip explants were surface sterilized with $0.04 \%$ mercuric chloride $\left(\mathrm{HgCl}_{2}\right)$ for 30 minutes, and then rinsed thoroughly three times over 15 minutes with sterile water, to remove the traces of mercuric chloride.

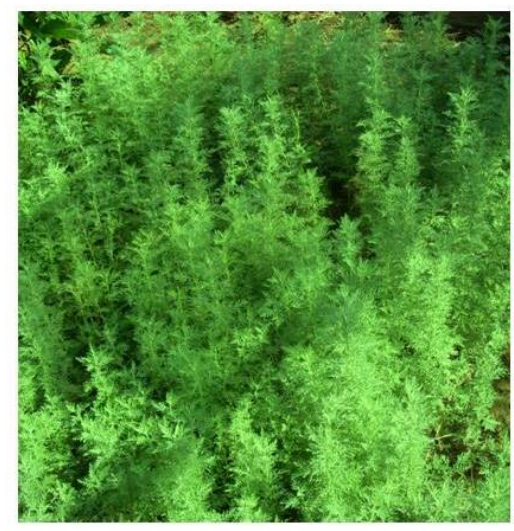

Figure 1 Mother plants of $A$. annua 


\subsection{Shoot initiation and multiplication}

Stem tips of A. annua were cultivated on MS medium supplemented with $7.0 \mathrm{~g} / \mathrm{L}$ agar, $3.0 \%$ sucrose and $0.2 \mathrm{mg} / \mathrm{L} \mathrm{GA} 3$ for three weeks, for growth and development. Shoots were further transferred on the medium containing BAP at three different concentrations $(0.5,1.0$ and $1.5 \mathrm{mg} / \mathrm{L})$ to study their response on the shoot multiplication (Table 1). The multiple initiated shoots were subcultured every four weeks on the same medium and maintained under the same conditions. After four weeks of cultivation, the percentage of formed shoots was determined, as well as the height and the average number of shoots per explant.

\subsection{Induction of roots formation and ex vitro acclimatization}

The in vitro shoots were cultivated on half strengths MS medium, supplemented with $7.0 \mathrm{~g} / \mathrm{L}$ agar, $2.0 \%$ and $3.0 \%$ sucrose (control variants), and IBA for rooting of $A$. annua (Table 2). IBA was used at a concentration of $0.1 \mathrm{mg} / \mathrm{L}$ to study its effect on the root formation. Each treatment included 20 plants. The percentage of root formation, number of roots per plant and root length was recorded after five weeks of cultivation. For acclimatization under ex vitro conditions, the rooted plants were carefully taken out from the vessels and washed under running tap water to remove the adhering gelling agent. They were transplanted to small plastic pots $(8 \mathrm{~cm}$ diameter $)$ containing soil: sand: perlite at the volume ratio 2: $1: 1 \mathrm{v} / \mathrm{v} / \mathrm{v}$. The potted plants were covered with a transparent polythene membrane to ensure high humidity (90\%) and opened after three weeks. The survival rate of the acclimatized plants was determined after five weeks. After two months of ex vitro acclimatization, the plants were transferred to greenhouse for further growth and development.

\subsection{Total phenolic and flavonoid content assay}

The total phenolic content was determined by the Folin-Ciocalteu method [29] and gallic acid was used the reference standard compound. The flavonoid content was measured after the aluminium chloride colorimetric method [30], with quercetin used to create the standard curve. The total antioxidant activity was measured according to Prieto et al. [31].

\subsection{Culture conditions}

After adding all components, the pH of the medium was adjusted to 5.8 with $1 \mathrm{~N} \mathrm{NaOH}$ or $1 \mathrm{~N} \mathrm{HCl}$. Sterilization of the medium was performed in an autoclave at $121{ }^{\circ} \mathrm{C}$ for $20 \mathrm{~min}$ at a pressure of $1.1 \mathrm{~kg} \mathrm{~cm}^{-2}$. The in vitro cultures were maintained under growth room conditions at a temperature of $22 \pm 2{ }^{\circ} \mathrm{C}$, relative humidity of $70 \%$ and a $16 / 8 \mathrm{~h}$ photoperiod under $40 \mu \mathrm{mol} \mathrm{m}^{-2} \mathrm{~s}^{-1}$ illumination provided by Philips $36 \mathrm{~W}$ cool white fluorescent tubes. The ex vitro plants were maintained in a growth chamber at a temperature of $24 \pm 2{ }^{\circ} \mathrm{C}$ under $16 / 8 \mathrm{~h}$ photoperiod and fluorescent light illuminations of $50 \mu \mathrm{mol} \mathrm{m}^{-2} \mathrm{~s}^{-1}$.

\subsection{Statistical analysis}

The data were averaged of triplicate measurements. Each treatment involved 20 plants. The data were statistically analyzed using analysis of variance (ANOVA) for comparison of means, and significant differences were calculated according to Fisher's least significance difference test at the $5 \%$ significance level using a statistical software package (Statgraphics Plus, version 5.1 for Windows). All data are presented as means standard error.

\section{Results}

\subsection{Shoot initiation and multiplication}

Cultivation of A. annua stem tips in vitro did not show any bacterial contamination due to the successful sterilization with $0.04 \% \mathrm{HgCl}_{2}$ bringing it to aseptic conditions (100\%). The frequency of shoot formation depends on the type of explant and the composition of the medium. Shoot initiation was performed on MS medium supplied by $0.2 \mathrm{mg} / \mathrm{L} \mathrm{GA} 3$ for growth and development. The shoots of $A$. annua cultured on MS medium containing different cytokinin concentrations, BAP at different concentrations $(0.5,1.0$ and $1.5 \mathrm{mg} / \mathrm{L})$ for multiplication stage. The maximum frequency (95\%) was observed on MS medium supplemented with $1.0 \mathrm{mg} / \mathrm{L}$ BAP, which induced number of shoots (19.1) with a shoot height $(3.6 \mathrm{~cm}$ ) after four weeks of cultivation (Table 1, Figure 2a, b).

These results showed that micropropagation of Artemisia required higher cytokinin concentration. MS medium fortified with $1.0 \mathrm{mg} / \mathrm{L}$ BAP was very effective in the successful shoot induction and multiplication. The shoots that were cultured on MS medium with $0.5 \mathrm{mg} / \mathrm{L}$ BAP, showed less shoot induction with average number of shoots 8.2 with average shoot height $2.7 \mathrm{~cm}$. MS medium with $1.5 \mathrm{mg} / \mathrm{L}$ BAP produced shoots with average number of shoots 10.5 with average shoot 
height $3.1 \mathrm{~cm}$. The tested cytokinins at a concentration of 0.5 and $1.5 \mathrm{mg} / \mathrm{L}$ BAP were less effective at the in vitro multiplication stage compared with the addition of $1.0 \mathrm{mg} / \mathrm{L} \mathrm{BAP.}$

Table 1 Effect of BAP on the micropropagation of A. апnua shoots after four weeks of cultivation

\begin{tabular}{llll}
\hline BAP (mg/L) & $\begin{array}{l}\text { Micropropagation rate } \\
\text { (\%) }\end{array}$ & $\begin{array}{l}\text { Average number of } \\
\text { shoots per explant }\end{array}$ & $\begin{array}{l}\text { Average shoots height } \\
\text { (cm) }\end{array}$ \\
\hline 0.5 BAP & 65 & $8.2 \pm 0.70^{\mathrm{a}}$ & $2.7 \pm 0.23^{\mathrm{a}}$ \\
$1.0 \mathrm{BAP}$ & 95 & $19.1 \pm 0.85^{\mathrm{c}}$ & $3.6 \pm 0.28^{\mathrm{b}}$ \\
$1.5 \mathrm{BAP}$ & 80 & $10.5 \pm 0.82^{\mathrm{ab}}$ & $3.1 \pm 0.26^{\mathrm{b}}$ \\
\hline
\end{tabular}

The data are presented as means of 20 plants per treatment \pm standard error. Different letters indicate significant differences assessed by Fisher test (5\%) after performing ANOVA multifactor analysis.

\subsection{Induction of root formation and ex vitro acclimatization}

For root induction, individual shoots were placed on the $1 / 2$ MS medium supplemented with $3.0 \%$ and $2.0 \%$ surcuse (controls) and with $0.1 \mathrm{mg} / \mathrm{L}$ IBA (Table 2). The controls showed $60-70 \%$ rooting, average number of roots 2.6 and 4.2 , respectively, and average root length of $1.6 \mathrm{~cm}$ and $2.5 \mathrm{~cm}$, respectively. The second control was proved to be better than the first one in terms of the plant rooting. The effect of auxin concentration on the root formation of $A$. annua was studied. The shoot rooting was observed on $1 / 2$ MS medium with $2.0 \%$ sucrose containing $0.1 \mathrm{mg} / \mathrm{L} \mathrm{IBA}-$ it caused $100 \%$ rooting, average number of roots 7.4, with average root length of $15.1 \mathrm{~cm}$ per shoot (Table 2, Figure 2c, d, e).

Table 2 Effect of IBA on the plant root induction of A. annua after five weeks of cultivation

\begin{tabular}{|c|c|c|c|}
\hline IBA (mg/L) & Rooting (\%) & $\begin{array}{l}\text { Average number of } \\
\text { roots plant }\end{array}$ & $\begin{array}{l}\text { Average root length } \\
(\mathrm{cm})\end{array}$ \\
\hline Control, $1 / 2$ MS+3.0\% sucrose & 60 & $2.6 \pm 0.21^{b}$ & $1.6 \pm 0.12^{\mathrm{a}}$ \\
\hline Control, $1 / 2 \mathrm{MS}+2.0 \%$ sucrose & 70 & $4.2 \pm 0.38^{\mathrm{ab}}$ & $2.5 \pm 0.24^{b}$ \\
\hline $1 / 2 \mathrm{MS}+0.1 \mathrm{IBA}+3.0 \%$ sucrose & 85 & $5.1 \pm 0.46^{\mathrm{a}}$ & $3.9 \pm 0.32^{c}$ \\
\hline $1 / 2 \mathrm{MS}+0.1 \mathrm{IBA}+2.0 \%$ sucrose & 100 & $7.4 \pm 0.67^{c}$ & $15.1 \pm 0.93^{\mathrm{ab}}$ \\
\hline
\end{tabular}

In that study we established that the $1 / 2$ MS medium induced more effectively roots than full MS medium (the results not shown). The root induction observed on $1 / 2$ MS with $0.1 \mathrm{mg} / \mathrm{L}$ of IBA with $3.0 \%$ surcuse was characterized by average number of roots 5.1 and average root length of $3.9 \mathrm{~cm}$. The $1 / 2 \mathrm{MS}$ medium supplemented with $0.1 \mathrm{mg} / \mathrm{L} \mathrm{IBA}+2.0 \%$ sucrose demonstrated a better response - the highest rooting percentage (100\%), as well as the longest root formation $(15.1 \mathrm{~cm})$ than $1 / 2 \mathrm{MS}+0.1 \mathrm{mg} / \mathrm{L} \mathrm{IBA}+3.0 \%$ sucrose, within five weeks of cultivation.

The survival of $A$. annua plants after two months under ex vitro conditions was evaluated (Figure $2 \mathrm{f}$ ). In vitro developed shoots (from $1 / 2$ MS medium with $2.0 \%$ sucrose and $0.1 \mathrm{mg} / \mathrm{L} \mathrm{IBA}$ ) were harvested and washed with running tap water. The plants revealed good ex vitro adaptability on potting mixture consisted of soil, perlite and sand $(2: 1: 1 \mathrm{v} / \mathrm{v} / \mathrm{v})$, which was found to be most appropriate for ex vitro adaptation. Initially, the rooted plants were transferred to plastic pots with mixture substrate and kept covered with polyethylene membranes for three weeks. The high levels of relative humidity enhanced the initial survival of the potted plants. Positive effect of this mixture on plant growth and development was observed during the first week after planting. At the acclimatization stage, the survival percentage of the microplants was 65\%. The plants were successfully hardened and transferred to greenhouse conditions. In vitro propagation is often restricted by high percentage of plant loss when transferred from in vitro to ex vitro conditions. Both factors are of great importance for the success of ex vitro adaptation: availability of well-developed roots and controlled reduction of humidity. Well-developed root system of the micropropagated plants and the appropriate substrate provides rapid acclimatization at ex vitro conditions. 


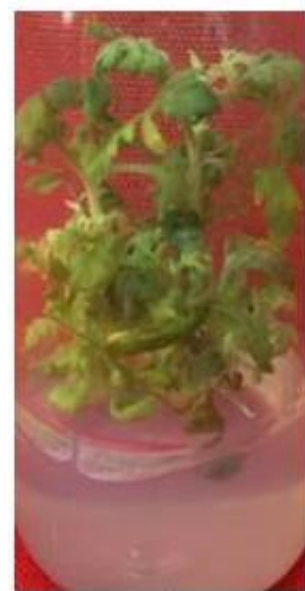

a

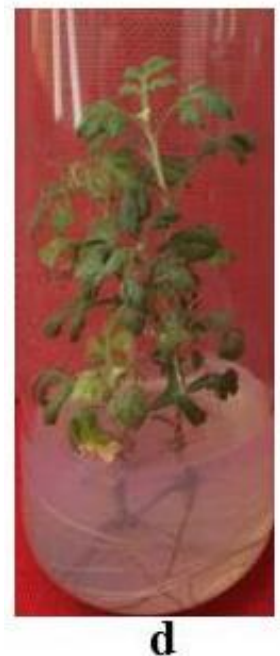

d

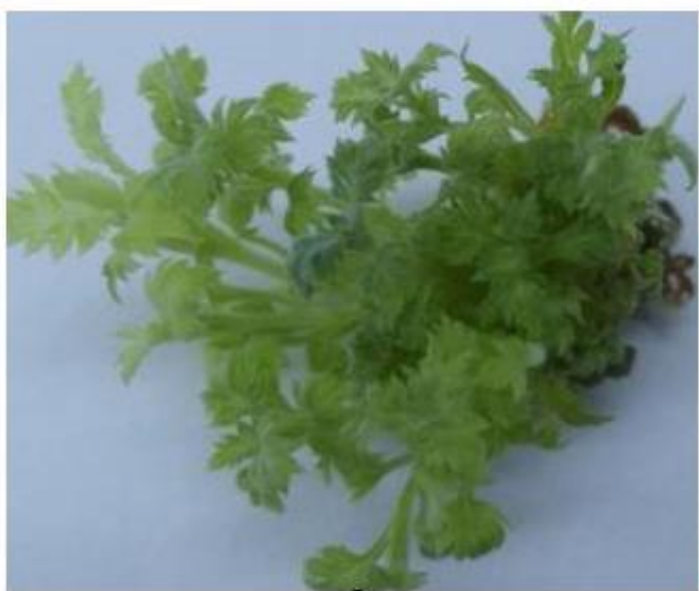

b

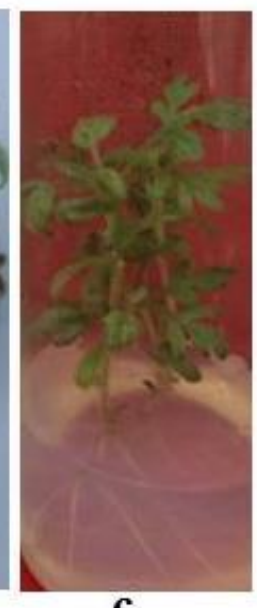

c

Figure 2 Micropropagation of $A$. annua: a) Shoot formation on MS medium supplemented with $1.0 \mathrm{mg} / \mathrm{L}$ BAP after two weeks of cultivation; b) Shoot formation on MS medium supplemented with $1.0 \mathrm{mg} / \mathrm{L}$ BAP after four week of cultivation; c) Rooted plants on $1 / 2 \mathrm{MS}$ medium supplemented with $0.1 \mathrm{mg} / \mathrm{L} \mathrm{IBA}+2.0 \%$ sucrose after two weeks of cultivation; d) and e) Rooted plants on $1 / 2 \mathrm{MS}$ with $0.1 \mathrm{mg} / \mathrm{L}+2.0 \%$ sucrose after five weeks of cultivation; f) Ex vitro acclimatized plants in soil: sand: perlite $(2: 1: 1 \mathrm{v} / \mathrm{v} / \mathrm{v})$ after two months.

\subsection{Antioxidant activity}

The evaluation of secondary metabolites' content in the shoots of in vitro cultivated A. annua showed that both, total phenols and flavonoids accumulated in a higher extent in the plants grown on the medium $1 / 2 \mathrm{MS}+0.1 \mathrm{mg} / \mathrm{L} \mathrm{IBA}+2.0 \%$ sucrose, as compared to the other two growth media (Table 3). The phenolic content was particularly increased - it was $23 \%$ above the variant with $1.0 \mathrm{mg} / \mathrm{L}$ BAP. These changes in the metabolic composition were accompanied by an increase of the total antioxidant activity (TAA), as well. TAA in the tissues of $A$. annua grown on $1 / 2 \mathrm{MS}+0.1 \mathrm{mg} / \mathrm{L} \mathrm{IBA}+$ $2.0 \%$ sucrose, was nearly $30 \%$ increased as compared to the plants grown on $1.0 \mathrm{mg} / \mathrm{L} \mathrm{BAP} \mathrm{(Table} \mathrm{3).}$

The next step of our research was to reveal the potential changes in the metabolic composition of the plants, that were ex vitro adapted to soil substrate after in vitro cultivation on $1 / 2 \mathrm{MS}+0.1 \mathrm{mg} / \mathrm{L} \mathrm{IBA}+2.0 \%$ sucrose. Ex vitro A. annua plants were very similar to the parental plants, in fact they did not differ from the in vivo plants in regards to secondary metabolites' content and total antioxidant activity (Figure 3,4). It was measured only an insignificant increase of the TAA level in the ex vitro plants. However, the values of the parameters that were examined, proved to be significantly lower during in vitro cultivation - $66 \%$ decrease of phenolic content and $36 \%$ decrease of the level of flavonoids were measured (Figure 3). TAA was also affected even in a lesser extent - it was 25\% lower in the shhots of in vitro A. annua plants (Figure 4). 
Table 3 Content of total phenols, flavonoids and antioxidant activity of A. annua

\begin{tabular}{llll}
\hline Variant & $\begin{array}{l}\text { Phenols } \\
\left(\mathbf{m g ~ g}^{-1} \mathbf{~ D W}\right)\end{array}$ & $\begin{array}{l}\text { Flavonoids } \\
\left(\mathbf{m g ~ g}^{-1} \mathbf{~ D W}\right)\end{array}$ & $\begin{array}{l}\text { Total antioxidant activity } \\
\text { (TAA) (mM g-1 DW) }\end{array}$ \\
\hline MS+1.0 mg/L BAP & $39.92 \pm 1.66$ & $7.03 \pm 0.28$ & $65.34 \pm 2.53$ \\
& $100 \%$ & $100 \%$ & $100 \%$ \\
$1 / 2 \mathrm{MS}+3.0 \%$ sucrose+0.1 mg/L IBA & $44.03 \pm 2.13$ & $6.67 \pm 0.29$ & $72.53 \pm 3.40$ \\
& $110.3 \%$ & $94.9 \%$ & $111 \%$ \\
$1 / 2 \mathrm{MS}+2.0 \%$ sucrose+0.1 mg/L IBA & $49.05 \pm 2.01$ & $7.70 \pm 0.31$ & $79.75 \pm 3.27$ \\
& $122.9 \%$ & $109.5 \%$ & $127.9 \%$ \\
\hline
\end{tabular}

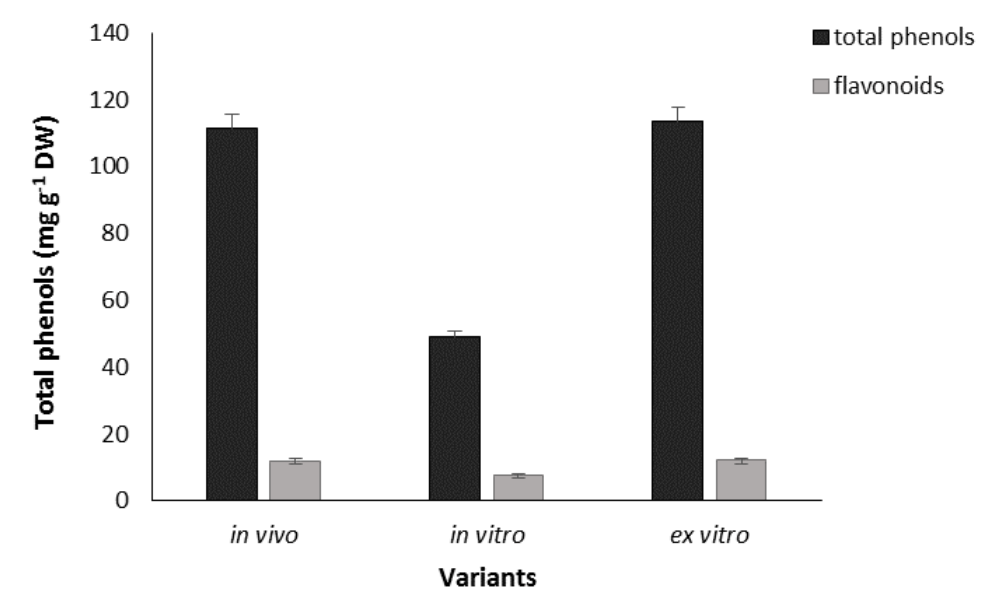

Figure 3 Total phenol ( $\left.\mathrm{mg} \mathrm{g}^{-1} \mathrm{DW}\right)$ and flavonoid content $\left(\mathrm{mg} \mathrm{g}^{-1} \mathrm{DW}\right)$ in the shoots of $A$. annua grown at different cultivation conditions

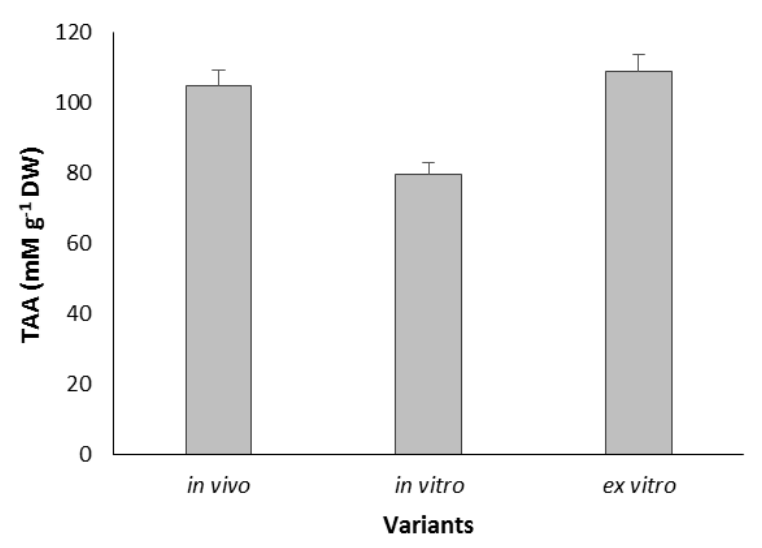

Figure 4 Total antioxidant activity $\left(\mathrm{mM} \mathrm{g}^{-1} \mathrm{DW}\right)$ in the shoots of $A$. annua grown at different cultivation conditions

\section{Discussion}

In the present study, an efficient protocol for micropropagation of the medicinal plant $A$. annua using stem tip explants, was described. It was reported that treatment by $0.1 \%$ mercuric cloride for three minutes was effective enough to remove the microbe contaminants from shoot tip and nodal explants, aiming to initiate an in vitro aseptic culture [32]. 
However, in our experiments, surface sterilization with $0.04 \% \mathrm{HgCl}_{2}$ for 30 minutes was successful in providing completely contamination-free shoots.

It was established that when the BAP concentration was gradually increased, the multiplication rate of $A$. annua was reduced to a greater extent [33]. The MS medium supplied with BAP provided shoots with no vitrification features and stimulated growth rate of $A$. annua stem tip explants. There have been some successful reports on tissue culture and micropropagation of A. аnnua [16, 34, 9]. Meanwhile, the potential combination of BAP and NAA for in vitro shoot induction and multiplication has been reported [35]. The investigations showed that the shoot formation occurred on MS medium supplied with BAP and thidiazuron (TDZ) at different concentrations, were effective enough to induce micropropagation of $A$. annua. A maximal response was observed on a MS medium containing $1.0 \mathrm{mg} / \mathrm{L} \mathrm{TDZ}$, where the highest number of shoots per explant was formed [9]. Highest micropropagation percent of $A$. annua leaf primordial was observed when full strength MS media supplemented with a combination of $1.5 \mu \mathrm{m} / \mathrm{L} \mathrm{GA}_{3}$ and $0.5 \mu \mathrm{m} / \mathrm{L}$ BAP, was used [36]. The highest percentage (98.75) of shoot induction was observed in the case when nodal explants cultured on MS supplemented with $0.8 \mathrm{mg} / \mathrm{L}$ BAP + $0.1 \mathrm{mg} / \mathrm{L}$ IBA. MS supplemented with $0.8 \mathrm{mg} / \mathrm{L} \mathrm{BAP}$ or $0.8 \mathrm{mg} / \mathrm{L} \mathrm{TDZ}$, used alone or in combination with $0.1 \mathrm{mg} / \mathrm{L} \mathrm{IBA}$, was found to be the most appropriate medium for in vitro shoot initiation of $A$. annua, derived from shoot tip and from nodal explants [37]. The nodal segments with axillary bud cultured on MS basal medium fortified with $1.5 \mathrm{mg} / \mathrm{L} \mathrm{BAP}+0.5 \mathrm{mg} / \mathrm{L}$ NAA facilitated favorable shoot induction [38]. High percentages of direct regeneration of $A$. annua were obtained from leaf and stem explants on a medium supplemented by $1.5 \mathrm{mg} / \mathrm{L}$ BAP and $0.05 \mathrm{mg} / \mathrm{L} \mathrm{NAA}$ [39].

IBA is now recognized as the most suitable plant growth regulator for root induction of $A$. annua. Our expeiments showed that the $1 / 2$ MS medium supplemented with $0.1 \mathrm{mg} / \mathrm{L}$ IBA $+2.0 \%$ sucrose resulted in the highest percentage and the longest root formation, in comparison with the medium containing $0.1 \mathrm{mg} / \mathrm{L} \mathrm{IBA}+3.0 \%$ sucrose (Table 2). The shoots of A. annua transferred to rooting medium containing $1.0 \mathrm{mg} / \mathrm{L}$ of IBA showed satisfactory rooting percentage (75\%) and good root quality [9]. Maximum number of $A$. annua roots (12 roots/shoot) was noted to be obtained in the medium containing $0.9 \mathrm{mg} / \mathrm{L}$ IBA [33]. Best rooting with average values of 18.25 explant root number and root length $6.35 \mathrm{~cm}$ was recorded on $1 / 2 \mathrm{MS}+0.5 \mathrm{mg} / \mathrm{L}$ IBA. The medium supplemented with also $1.0 \mathrm{mg} / \mathrm{L}$ of IBA, showed efficient root induction and further development of healthy roots [38]. In our studies, the effect of $0.1 \mathrm{mg} / \mathrm{L} \mathrm{IBA} \mathrm{in} 1 / 2 \mathrm{MS}$ medium on rooting have been reported for some other medicinal plants, such as Stevia rebaudiana Bertoni $[18,19]$. Further, the in vitro plants of $A$. annua were successfully ex vitro acclimated and, it was important to emphasize, that no phenotypic variations were observed in the propagated plants which remained morphologically similar. Several researchers $[9,30$, $34,35]$ also reported that rooted $A$. annua shoots growed normally after their transfer to greenhouse.

Nowadays, the increased interest in medicinal plants is also a result of understanding the phytochemicals as new natural antioxidants. Their application in food and pharmaceutical industry is considered very promising to replace synthetic antioxidants, which are being restricted for potential health risks and toxicity [40, 41]. To determine the antioxidative properties of $A$. апnиa, we preferred methanol as the most favorable extractant because of the highest radical scavenging and lowest lipid peroxidation observed in methanolic extracts [42, 43]. It is established that $A$. annua is among the medicinal plants with the highest oxygen radical absorbance capacity $[44,45]$ and the high antioxidant activity of the extracts is probably due to the high phenolic content. Over 50 different phenolic compounds belonging to five major groups have been reported from A. annua [23].

Although artemisinin is considered as a major bioactive component present in this Chinese herb, the flavonoids have shown a variety of biological activities [26]. A. annua is also a rich source of antioxidant flavonoids that are thought to play an important role in potentiating the effects of artemisnin drugs against cancer and parasitic diseases [23]. A. annua is currently the only commercial source of the sesquiterpene lactone artemisinin. As it cannot be synthesized chemically in an economically feasible way, most of artemisinin-related interests have focused on A. annua which actually contains low amounts of artemisinin $[46,47]$ far from enough in the international markets.

We have found that during in vitro cultivation, in the stems of $A$. annua grown on $1 / 2 \mathrm{MS}+0.1 \mathrm{mg} / \mathrm{L} \mathrm{IBA}+2.0 \%$ sucrose, along with the best plant rooting, a maximum amounts of phenols and flavonoid were observed. Moreover, the phenolic content was increased to a greater extent than flavonoids (Table 3). Total antioxidant activity in the stems and leaves of $A$. annua changed in a similar way and that enhancement could be an indication of the possible oxidative stress occurred under these cultivating conditions. The high positive correlation between antioxidant capacities and total phenolic content could imply that phenolic compounds are a major contributor to the antioxidant activity of $A$. annua plants.

In comparisons with the in vivo plants, it was seen that ex vitro A. annua shoots did not change their levels of total phenolic and flavonid contents (Figure 3), and only a slight increase of TAA was observed (Figure 4). As might be 
expected, the parameters that were studied, were significantly lower in the in vitro cultivated plants - it was found $66 \%$ decrease of total phenols and 36\% decrease of flavonoids, while TAA remained less affected (Figure 3, 4). It was reported $[48,49]$ that extracts of some in vitro cultivated medicinal plants contained less amounts and less variety of secondary metabolites. Thus, the alterations observed in bioactive substances under different growth conditions, could suggest their possible involvement in the processes of adaptation and surviving in changing environments.

\section{Conclusion}

The relatively low yield of artemisinin in A. annua L. limits the commercialization of the drug worldwide. Therefore, the researchers' efforts are aimed at increasing the yield of biomasss and its antioxidant properties. In our study, we were able to develop an effective protocol for mass micropropagation of $A$. annua. To achieve the highest multiplication of the stem tips, MS medium supplemented by $1.0 \mathrm{mg} / \mathrm{L}$ BAP was recommended. The highest level of rooting was obtained after cultivation on $1 / 2 \mathrm{MS}+0.1 \mathrm{mg} / \mathrm{L}$ IBA $+2.0 \%$ sucrose and the rooted plants were further successfully ex vitro acclimated. There were not observed any differences between the parental, in vitro and ex vitro adapted plants, regarding their morphological and growth characteristics. The contents of total phenols and flavonoids were lowered during in vitro cultivation, but after ex situ acclimatization restored to the levels of in vivo plants. Generally, our research indicated that the in vitro technique described here, provided a promising method for rapid propagation of $A$. annua as a source of biomass containing valuable bio-active compounds for medicinal and pharmaceutical needs.

\section{Compliance with ethical standards}

\section{Acknowledgments}

Authors would like to thank all staff members for their cooperation throughout the experimental period.

\section{Disclosure of conflict of interest}

The authors declare that they have no conflict of interests.

\section{References}

[1] Tiruneh G, Kebede Y and Yigzaw T. (2010). Use of plant Artémisia annua as a natural anti-malarial herb in Arbaminch Town (Ethiopia), Journal of Health and Biomedical Sciences, 2(2), 75-82.

[2] Pamela JW, Arsenault RP, Covello SP, McMickle A, Teoh HK and Reed WD. (2011). Artemisinin production in Artemisia annua: studies in planta and results of a novel delivery method for treating malaria and other neglected diseases, Phytochemistry Reviews, 10(2), 173-183.

[3] Juteau F, Masotti V, Bessiere JM, Dherbomez M and Viano J. (2002). Antibacterial and antioxidant activities of Artemisia annua essential oil. Fitoterapia, 73, 532-535.

[4] Firestone GL and Sundar SN. (2009). Anticancer activities of artemisinin and its bioactive derivatives. Expert Reviews in Molecular Medicine, 30(11), 32-36.

[5] Das KA. (2015). Anticancer effect of antimalarial artemisinin compounds. Annals of Medical and Health Science Research, 5(2), 93-102.

[6] Xie DY, Zou ZR, Ye HC, Li GF and Guo ZC. (2001). Selection of hairy root clones of Artemisia annua L. for artemisinin production. Israel Journal of Plant Sciences, 49, 129-134.

[7] Elhag H, EL-Feraly F, Mossa JS and Hafez M. (2006). In vitro propagation of Artemisia annua L. Journal of King Saud University, 3, 251-259.

[8] Lualon W, De-Ekankerl W and Tanaka H. (2008). Artemisinin production by shoot regeneration of Artemisia annua L. Zeitschrift für Naturforschung, 63, 96-100.

[9] Almaarri $\mathrm{K}$ and Yu Xie. (2010). In vitro direct organogenesis and micropropagation of Artemisia annua. J. Biotechnologie Vegetale, 26, 327-337.

[10] Murashige, T. and Skoog, F. (1962). A revised medium for rapid growth and bio assays with tobacco tissue cultures. Physiologia Plantarum, 115, 493-497. 
[11] Jamaleddine ZO, Lyam P, Fajimi O, Giwa A, Aina A, Lawyer EF, Okere AU and Odofin WT. (2011). In vitro growth response of Artemisia annua seeds to different concentrations of plant growth regulators. African Journal Biotechnology, 10, 17841-17844.

[12] Lee YM, Hisiao G, Chang JR and Yen MH. (2003). Regeneration of Egyptian medicinal plant Artemisia judicia L. Plant Cell Reports, 21, 525-530.

[13] Aslam NZ and Chaudhary MF. (2006). Callogenesis and direct organogenesis of Artemisia scoparia. Pakistan Journal of Biological Sciences, 9, 1783-1783.

[14] Govindaraj S, Kumary BD, Gioni PL and Flamini G. 2008. Mass propagation and essential oil analysis of Artemisia vulgaris, Journal of Bioscience and Bioengineering, 105(3), 176-183.

[15] Mannan A, Syed TN, Yameen MA, Ullah N, Ismail T, Hussain I and Mirza B. (2012). Effect of growth regulators on in vitro germination of Artemisia absinthium. Scientific Research and Essays, 7, 1501-1507.

[16] Sharafi A, Hashemi SH and Jourabchi E. (2007). Tissue culture and regeneration of Artemisia annua. Iranian Journal of Biology, 21, 565-573.

[17] Shinde S, Sebastian KJ, Jain RJ, Hanamanthagouda SM and Murthy NH. (2016). Efficient in vitro propagation of Artemisia nilagirica var. nilagirica (Indian wormwood) and assessment of genetic fidelity of micropropagated plants. Physiology and Molecular Biology of Plants, 22(4), 595-603.

[18] Zayova E, Stancheva I, Geneva M, Petrova M, Dimitrova L. (2013). Antioxidant activity of in vitro propagated Stevia rebaudiana Bertoni plants of different origins. Turkish Journal of Biology, 37, 106-113.

[19] Zayova E, Nedev T and Dimitrova L. (2017). In vitro storage of Stevia rebaudiana Bertoni under slow growth conditions and mass multiplication after storage. Bio Bulletin, 3(1), 30-38.

[20] Ştefanache C, Bujor O, Necula R, Dănilă D, Ciocârlan N, Ghendov V, Carlen C and Simonnet X. (2016). Phenolic content of Artemisia annua L. from natural habitats in republic of Moldova. Journal of Plant Development, 23, 6169.

[21] Cai, Y., Luo Q., Sun, M., Corke H. (2004). Antioxidant activity and phenolic compounds of 112 traditional chinese medicinal plants associated with anticancer. Life Science, 74, 2157-2184.

[22] Ivanescu B, Vlase L, Corciova A and Lazar MI. (2010). HPLC/DAD/MS study of polyphenols from Artemisia absinthium, A. annua, and A. vulgaris. Chemistry of Natural Compounds, 46(3), 468-470.

[23] Ferreira JFS, Devanand LDL, Sasaki T and Heyerick A. (2010). Flavonoids from Artemisia annua L. as antioxidants and their potential synergism with artemisinin against malaria and cancer. Molecules, 15, 3135-3170.

[24] Sytar O, Hemmerich I, Zivcak M, Rauh C and Brestic M. (2018). Comparative analysis of bioactive phenolic compounds composition from 26 medicinal plants. Saudi Journal of Biological Sciences, 25(4), 631-641.

[25] Zhu XX, Yang L, Li YL, Zhang D, Chen Y, Kostecka P, Kmonickova E and Zidek Z. (2013). Effects of sesquiterpene, flavonoid and coumarin types of compounds from Artemisia annua L. on production of mediators of angiogenesis. Pharmacological Reports, 65, 410-420.

[26] Skowyra M, Gallego MG, Segovia F and Almajano MP. (2014). Antioxidant properties of Artemisia annua extracts in model food emulsions. Antioxidants. 3(1), 116-128.

[27] Bautista I, Boscaiu M, Lidon A, Llinares JV, Lull C, Donat MP, Mayoral 0 and Vicente O. (2016). Environmentally induced changes in antioxidant phenolic compounds levels in wild plants. Acta Physiologiae Plantarum, 38, 1-9.

[28] Mierziak J, Kostyn K and Kulma A. (2014). Flavonoids as important molecules of plant interactions with the environment. Molecules. 19, 16240-16265.

[29] Singleton V, Orthofer R and Lamuela-Raventys R. (1999). Analysis of total phenols and other oxidation substrates and antioxidants by means of Folin-Chiocalteu reagent. Method Enzymol, 299, 152-178.

[30] Chang, C., Yang, M., Wen, H., Chern, J. (2002). Estimation of total flavonoid content in propolis by two complementary colorimetric methods. Journal of food and drug analysis, 10, 178-182.

[31] Prieto P, Pineda M and Aguilar M. (1999). Spectrophotometric quantitation of antioxidant capacity through the formation of a phosphomolybdenum complex: specific application to the determination of vitamin E. Analytical Biochemistry, 269, 337-341. 
[32] Sujata G and Kumari BD. (2007). Effect of phytohormones on micropropagation of Artemisia vulgaris L. Acta Physiologiae Plantarum, 29, 189-195.

[33] Ganesan CM and Paulsamy S. (2011). Standardized protocol for the in vitro culture of Artemisia annua L. - A medicinal plant at high altitudes of Nilgiris, the Western Ghats. Journal of Research in Biology, 3, 173-178.

[34] Banyai W, Kirdmanee C, Mii M and Supaibulwatana K. (2010). Overexpression of farnesyl pyrophosphate synthase (FPS) gene affected artemisinin content and growth of Artemisia annua L. Plant Cell, Tissue and Organ Culture, 103, 255-265.

[35] Geng S, Chun YH, Gufen L and Chong K. (2001). Flowering of Artemisia annua L. test tube plantlets and artemisinin production with shoot cluster induced from flower organs explants. Chinese Journal of Applied and Environmental Biology, 7, 201-206.

[36] Tahir SM, Usman IS, Katung MD and Ishiyaku MF. (2013). Micro Propagation of Wormwood (Artemisia annua L.) Using Leaf Primordia. Science World Journal, 8(1), 1-7.

[37] Hailu T, Abera B and Mariam E. (2013). In vitro mass propagation of artemisia (Artemisia annua L.) cv: Anamed. Plant Tissue Culture and Biotechnology, 23(2), 165-176.

[38] Gopinath B, Gandhi K and Saravanan S. (2014). In vitro propagation of an important medicinal plant Artemisia annua L. from axillary bud explants. Advances in Applied Science Research, 5(1), 254-258.

[39] Dangash A, Ram M, Niranjan R, Bharillya A, Misra H, Pandya N and Jain C. (2015). In vitro selection and hormonal regulation in cell culture of Artemisia annua L. JSM Cell and Developmental Biology, 3(1), 10-13.

[40] Katalinic V, Milos M, Kulisic T and Jukic M. (2006). Screening of 70 medicinal plant extracts for antioxidant capacity and total phenols. Food Chemistry, 94 (4), 550-557.

[41] Kopjar M, Piližota V, Hribar J and Simcic M. (2009). Total phenol content and antioxidant activity of water solutions of plant extracts. Croatian Journal of Food Science and Technology, 1, 1-7.

[42] Brisibe, E., Umoren, U., Brisibe, F., Magalhäes, P., Ferreira, J., Luthria, D., Wu, X., Prior, R. (2009). Nutritional characterisation and antioxidant capacity of different tissues of Artemisia annua L. Food Chemistry, 115, 12401246.

[43] Iqbal S, Younas U, Chan KW, Haq Z and Ismail M. (2012). Chemical composition of Artemisia annua L. leaves and antioxidant potential of extracts as a function of extraction solvents. Molecules, 17, 6020-6032.

[44] Zheng W and Wang S. (2001). Antioxidant activity and phenolic compounds in selected herbs. Journal of Agricultural and Food Chemistry, 49, 5165 - 5170.

[45] Baraldi R, Isacchi B, Predieri S, Marconi G, Vincieri F and Bilia A. (2008). Distribution of artemisinin and bioactive flavonoids from Artemisia annua L. during plant growth. Biochemical Systematics and Ecology, 36, 340-348.

[46] Kindermans J, Pilloy J, Olliaro P and Gomes M. (2007). Ensuring sustained ACT production and reliable artemisinin supply. Malaria Journal, 6, 125-130.

[47] Sharafi A, Hashemi SH, Sharafi AA, Azadi P and Mousavi A. (2014). Tissue culture and regeneration of an antimalarial plant, Artemisia sieberi Besser, Research Journal of Pharmacognosy, 1(3), 15-20.

[48] Hristova L, Doichinova Z, Damyanova E and Kapchina-Toteva V. (2013). Effect of 6-benzylaminopurine on micropropagation of Artemisia chamaemelifolia Vill. (Asteraceae). Bulgarian Journal of Agricultural Science, 19(2), 57 - 60.

[49] Yordanova Z, Rogova M, Zhiponova M, Georgiev M and Kapchina V. (2017). Comparative determination of the essential oil composition in Bulgarian endemic plant Achillea thracica Velen. during the process of ex situ conservation. Phytochemistry Letters, 20, 456-461.

\section{How to cite this article}

Zayova EG, Nedev TA, Petrova DH, Zhiponova MK and Chaneva GT. (2018). Efficient protocol for mass micropropagation of Artemisia annua L. GSC Biological and Pharmaceutical Sciences, 5(2), 59-68. 